\title{
Entre o curso tradicional e o curso experimental da Faculdade de Medicina-USP: a experiência da pedagoga Maria Cecília Ferro Donnangelo, 1968-1976
}

\section{Between the traditional and the experimental courses of USP Medical School: the experience of the educator Maria Cecília Ferro Donnangelo, 1968-1976}

\author{
André Mota ${ }^{1}$
}

\begin{abstract}
RESUMO
As mudanças trazidas pela ditadura militar no Brasil alteraram de forma decisiva a vida institucional da Faculdade de Medicina da USP. Entre a complexidade de uma escola médica sob a pressão político-institucional que se instaurava, a criação de um curso médico capaz de oferecer a formação de um "novo" profissional, movimento nascido das hostes oposicionistas ao regime, redundou numa divisão curricular e de seus alunos. De um lado o curso que vinha se dando até então, o Curso Tradicional, por outro lado uma proposta curricular do então chamado Curso Experimental, que mesmo tendo uma vida curta, entre 1968-1974, possibilitou uma série de experiências nunca pensadas ou permitidas no que dizia respeito ao ensino e prática da medicina. Dentre os professores interessados em alavancar tal proposta inovadora, é interessante notar a presença de Maria Cecília Ferro Donnangelo, figura intelectual das mais relevantes no campo da Saúde Coletiva brasileira e que teve sua trajetória biográfica entrelaçada a esse acontecimento de dimensão pedagógica e política. Acompanhar tal experiência, entre avanços e recuos, faz parte da centralidade deste estudo.
\end{abstract}

Palavras-chave: Currículo Médico; Curso Experimental da FMUSP; Maria Cecília Ferro Donnangelo; História da Educação Médica.

DOI: $10.1590 / 0104-4060.37808$

1 Universidade de São Paulo. Departamento de Medicina Preventiva da Faculdade de Medicina. São Paulo, São Paulo, Brasil. Av. Dr. Arnaldo, n. ${ }^{\circ} 455,4 .^{\circ}$ andar. CEP: 01246-903. 


\begin{abstract}
The changes brought about by the military dictatorship in Brazil altered in a decisive fashion the institutional life of the USP Medical School. Amid the complexity of a medical school under mounting political and institutional pressure, the creation of a medical course capable of forming a "new" professional - a movement born from the hosts opposed to the regime-resulted in a rupture both in its curriculum and among its students. On one side, there was the course that had been taught so far, the Traditional Course, on the other side, a curriculum proposal of the then-called Experimental Course, which, even though short-lived (1968-1974), made possible a series of experiences never thought of before or permitted as far as the teaching and the practice of medicine were concerned. It is worth noting, from among the professors interested in promoting such an innovative proposal, the presence of Maria Cecília Ferro Donnangelo, one of the most prominent intellectual figures in the field of Collective Health in Brazil, whose biographical trajectory was intertwined with that event of pedagogical and political dimensions. Following such an experience, in its advances and retreats, is a central part of this study.
\end{abstract}

Keywords: Medical Curriculum; USP Medical School Experimental Course; Maria Cecília Ferro Donnangelo; History of Medical Education.

\title{
Introdução
}

Quando Maria Cecília Ferro Donnangelo escreveu seu Currículo Vitae, em 1982, as primeiras informações autobiográficas falavam de seu nascimento em 19 de agosto de 1940 na cidade de Araraquara, ou seja, em plena ditadura do Estado Novo varguista. Cursou nessa cidade o primário, o secundário e o normal no Colégio Progresso, entre os anos de 1948 e 1958, período já de redemocratização do país, tendo a política desenvolvimentista da época o desafio de dar o "salto modernizante" de que o Brasil precisaria. Com essas expectativas em pauta, Donnangelo cursou o científico no Colégio Duque de Caxias entre 1956 e 1958, prestando exame vestibular na Faculdade de Filosofia, Ciências e Letras de Araraquara - em 1959, tendo sido classificada em primeiro lugar entre os candidatos ao Curso de Pedagogia (DONNANGELO, 1982, p. 3).

Em 1952, Araraquara tinha já 63.552 habitantes e era considerada uma cidade politicamente estável, com razoável qualidade de vida, grande oferta de serviços e uma organização educacional e cultural privilegiada. Tais dimensões, que poderiam redundar apenas num certo isolamento e provincianismo 
interiorano, sofreram uma reviravolta, fruto dos movimentos culturais juvenis nascentes e de sua atuação no sentido de "oxigenar" a cultura reinante, desafiando o conservadorismo e se voltando para experiências dentro e fora do país.

Essas contingências devem ter, aos poucos, adentrado o cotidiano da moça católica e normalista Cecília Donnangelo. Talvez não de forma determinante no Colégio Progresso, onde se impunha e exigia uma determinada postura austera e distante daquelas novidades. Terá sido o aparecimento de uma nova faculdade, voltada para o pensamento social, a se interpor na "rota natural" de uma moça de sua formação, oportunidade histórica ímpar vivenciada na então Faculdade de Filosofia, Ciências e Letras de Araraquara.

Criadas entre os anos de 1957 e 1959, as Faculdades de Ciências e Letras paulistas estavam atreladas a um processo de modernização do país e interiorização da industrialização do estado, o que exigia impulso no campo educacional, mesmo que houvesse um embate, bastante natural entre as hostes de suas elites, de que era uma guinada perigosa educar uma nova elite intelectual ao invés de apenas renovar, comme d'habitude, a já existente (VAIDERGORN, 1995).

No entanto, aqueles tempos pressionavam pela necessidade de formação e renovação do professorado interiorano, principalmente, voltado ao ensino secundário e à chance para alguns prosseguirem sua carreira acadêmica, especialmente, na Universidade de São Paulo (USP). Com esse quadro, foram criadas, em 1957, seis faculdades de filosofia, ciências e letras no interior paulista. A chamada Faculdade de Filosofia, Ciências e Letras de Araraquara (FFCLA) ${ }^{2}$ foi autorizada a funcionar em 13 de abril de 1959, iniciando suas atividades com os cursos de Pedagogia e de Letras. Uma novidade marcante dessa nova escola era o fato de rapidamente se ter estabelecido um diálogo entre as expectativas daqueles movimentos culturais reinantes e a vida acadêmica de uma Faculdade que logo ganha foros, inclusive, internacionais:

A Faculdade de Filosofia de Araraquara tem em seu currículo, entre outras realizações, a organização de uma conferência com o escritor e filósofo francês Jean-Paul Sartre. Sartre esteve na cidade no dia 4 de setembro de 1960, evento que contou com a presença de Simone de Beauvoir, sua mulher, acompanhados de Jorge Amado, Zélia Gattai, Bento Prado Junior, Fernando Henrique e Ruth Cardoso, entre outros intelectuais. Por sua localização à Rua 3, entre as Avenidas Duque de Caxias e Espanha, em frente ao Cine Odeon e muito próximo ao Teatro Municipal, a Faculdade de Filosofia não era uma escola isolada. Ao contrário, fazia parte de Araraquara, era ponto de encontro obrigatório dos grupos mais informados

2 A partir de 1976, a Faculdade passou a integrar a Universidade Estadual Paulista (Unesp). 
da cidade, mesmo que não estivessem cursando a escola (MEDINA JUNIOR, 2009, p. 202-203).

O curso de Pedagogia, consequência das licenciaturas e da formação de professores para escolas secundárias trazia, no bojo dessas necessidades regionais mais objetivas, uma rica discussão sobre os destinos da educação brasileira como suporte de desenvolvimento e modernização nacional, assunto capital para o campo pedagógico:

[...] percebemos as aproximações que se deram entre dois órgãos do mesmo ministério, que se destacaram no cenário nacional daquele momento: o INEP (na época denominado Instituto Nacional de Estudos Pedagógicos), que se ocupava da formulação das políticas para o ensino e da pesquisa educacional, e o ISEB (Instituto Superior de Estudos Brasileiros), que assumiu papel de referência na formulação do ideário desenvolvimentista que predominou no país, naquele contexto. O INEP e o ISEB foram referências institucionais importantes para a disseminação do pragmatismo e do desenvolvimentismo, respectivamente (MENDONÇA, 2006, p. 96).

As análises feitas pelos dois grupos se assemelhavam no que dizia respeito aos entraves e atrasos, ao mesmo tempo em que tentavam implementar medidas para superá-los por meio do sistema educacional, criando uma nova atmosfera cultural em todo o Brasil. Tais posições chegaram na Faculdade de Filosofia, Ciências e Letras de Araraquara, em larga medida, pelas mãos da Sociologia. Entre os motivos possíveis, estaria o curso de Sociologia da Faculdade de Filosofia, Ciências e Letras (FFCL)-USP, onde havia divergências teóricas vinculadas a uma reação de insatisfação reinante pela extrema dificuldade de inserção acadêmica que o regime de cátedras impunha aos recém-formados. Nesse contexto, jovens sociólogos saíram em busca de outras alternativas, chegando à nova faculdade em Araraquara e logo influenciando a vida acadêmica daquele alunado:

[...] o debate em torno de novas questões teóricas disseminou-se pelas FFLC-IIES na mesma época em que os cursos de Ciências Sociais eram criados. Os curricula, não só desse novo curso, passavam a incluir leitura de Hegel, Marx, Sartre, bem como elementos de Economia, esta com duplo intento: atualizar a formação geral (que se assemelhava à da USP) e entender melhor a realidade brasileira! (VAIDERGORN, 1995, p. 173). 
Um desses intelectuais foi Luiz Pereira, indicado à FFCLA por seu orientador, Florestan Fernandes. O doutorando Pereira naquele momento era formado em pedagogia, com mestrado no Departamento de Sociologia da USP ${ }^{3}$ :

Luiz Pereira, no curso de Pedagogia na Faculdade de Educação, cursara Sociologia, e também na Escola Normal, além de ter feito especialização e doutorado em Sociologia [...] o autodidatismo de Luiz e a voracidade com que se dedicou a atualizar e ampliar seus conhecimentos sociológicos, ainda em Araraquara, são boas indicações de uma competência que não se limitava aos temas da educação e sociologia da educação (CASTRO, 2010, p. 215).

O perfil de pedagogo e sociólogo da educação de Luiz Pereira se impõe nesta análise como ponto capital, pois foi um dos elementos a constituir sua relação intelectual e pessoal com a jovem estudante de pedagogia Cecília Donnangelo. Pereira lecionava no curso de pedagogia e instruía o campo sociológico pela apreensão da realidade escolar brasileira, apresentando o projeto $O$ magistério primário numa sociedade de classes, defendido como tese de doutorado na Faculdade de Filosofia, Ciências e Letras da Universidade de São Paulo (USP) em 1961 e publicado como O professor primário metropolitano (1963):

Essa pesquisa consistiu numa análise sociológica do magistério primário público estadual do município de São Paulo, na qual a profissão foi abordada como uma das categorias ocupacionais por meio das quais se processava a participação das mulheres oriundas das classes médias na população economicamente ativa de um centro urbano em intenso processo de urbanização e industrialização. Analisando os valores e as atitudes presentes na formação do normalista e na carreira no magistério, Luiz Pereira colaborou para desmistificar a figura dos "missionários do ensino", apresentando os professores primários como profissionais mal remunerados e desprestigiados, que enfrentavam os desafios colocados pelo processo de integração a uma sociedade urbano-industrial (FERREIRA, 2008, p. 287-288).

3 Sobre a constituição do Departamento de Sociologia da FFCL-USP e a influência intelectual de Florestan Fernandes e seu grupo, acompanhar debate em: Jackson (2007). 
Foi nesse contexto de produção crítica educacional, que houve o encontro de Luiz Pereira com Donnangelo: “[...] conheci Cecília em 1959, quando fui reger a disciplina de Sociologia na recém-criada Faculdade de Filosofia de Araraquara. Ela fez parte da primeira turma e, no $2 .^{\circ}$ ano, era quase minha auxiliar, tendo ajudado na tabulação dos dados de minha tese de doutorado" (PEREIRA, 1983, p. 22). Assim, parece-nos que, se era intermediado por metodologias sociológicas, esse diálogo tinha seu centro de convergência na reflexão educacional brasileira, especialmente na formação do professor. Para uma professora primária e secundarista formada sob bases de ensino católicas, acompanhar de tão perto a produção de conhecimento das pesquisas de Pereira, influenciaram a pedagoga Donnangelo a pensar uma nova educação.

\section{O Curso Experimental da FMUSP, 1968-1974: uma proposta de inovação pedagógica}

Em sua trajetória acadêmica posterior à Faculdade de Filosofia, Ciências e Letras de Araraquara, pouco se tem referido essa dimensão educacional de Cecília Donnangelo. A magnitude de sua formação pedagógica, decorrente do ambiente das questões educacionais brasileiras, como vimos aqui, foi muitas vezes eclipsada pela de cientista social, dimensão mais valorizada e interpretada, senão como única, como a mais atuante, criando, pelo desconhecimento histórico, um "pano de fundo biográfico", o que deve necessariamente afetar uma leitura mais refinada de suas próprias concepções sociológicas. Uma aproximação de sua entrada chegada à Faculdade de Medicina-USP reforça nosso olhar nessa direção.

O contato de Donnangelo com a medicina como objeto de suas preocupações e, posteriormente, como docente no Departamento de Medicina Preventiva da Faculdade de Medicina da Universidade de São Paulo (FMUSP), onde trabalhou durante dezesseis anos, resultou inicialmente dessa experiência escolar relacionada à sua atividade no magistério secundário. Como professora de sociologia e psicologia de uma Escola Normal Estadual e coordenadora dos programas do curso, projetou e supervisionou uma pesquisa integrada por várias áreas da escola, realizada por estudantes junto a alunos de escolas primárias e referente a problemas de nutrição e rendimento escolar, passagem bastante sugestiva de sua linhagem sociológica, vinda de Luiz Pereira, em que o trabalho de campo era um dos pilares considerados centrais para a formação de um sociólogo. 
Desse trabalho de pedagoga e socióloga, decorreram contatos com profissionais da área médica e um convite para proferir palestras na cadeira de Medicina Legal e Social da Faculdade de Medicina da Universidade de São Paulo, que então manifestava interesse pela implantação de um programa de ciências sociais no curso de graduação em medicina. Aos poucos, no entanto, foi ficando clara a orientação sociológica que se tentava implementar na Medicina Legal. Enfatizando aproximações de classificação comportamental, ao estilo de Nina Rodrigues, essa abordagem provocou um afastamento paulatino de Donnangelo, que se volta a um outro campo de saber médico, então denominado "Medicina Preventiva".

Assim, se Donnangelo havia entrado como professora da FMUSP em 1964, através da referida cadeira, com apenas uma interrupção, em 1965, quando colaborou na elaboração e implantação do primeiro programa de curso e pesquisas em sociologia rural da cadeira de economia da Escola Superior de Agricultura Luiz de Queiroz, da Universidade de São Paulo (MOTA; SCHRAIBER; SILVA, 2004), já em 1969, começou a trabalhar no recém-criado Departamento de Medicina Preventiva como "instrutora de ensino", a convite do então chefe do Departamento, o professor catedrático Guilherme Rodrigues da Silva. Nesse sentido, ela deu prioridade à formação, mesmo recebendo nesse processo severas críticas e intervenções da própria faculdade. E foi no denominado Curso Experimental de Medicina (CEM-USP), que Donnangelo propôs a incorporação e aprofundamento dos aspectos sociais no campo da medicina e da saúde.

O CEM-USP nasceu de uma solicitação, assinada por nove professores, à Congregação da Faculdade de Medicina, em 17 de outubro de 1966. Em 28 de março de 1967, o então diretor da Faculdade, João Alves Meira, aprovava a formação de uma Comissão de Orientação Didática do Curso Experimental de Medicina (CODCEM) e já em 5 de janeiro de 1968 seu memorial foi encaminhado ao governador do estado de São Paulo, pedindo a liberação de verbas especiais para a instalação do primeiro ano de suas atividades. Até 30 de abril de 1969, a coordenação geral do CEM-USP esteve sob a responsabilidade de Isaias Raw (LACAZ, 1999, p. 130).

Diante da novidade do ato, os alunos que fossem admitidos pelo vestibular seriam divididos em dois grupos distintos e poderiam escolher entre o curso tradicional, que seguia as diretrizes já formuladas pela Faculdade em períodos anteriores, e o curso experimental, com sua nova proposta de ensino para a formação médica. Nas palavras de Guilherme Rodrigues da Silva, um dos idealizadores do curso, o CEM-USP daria à FMUSP uma maior integração, bem como uma renovação curricular: 
[...] esse grupo era liderado por Eduardo Marcondes Machado, que pensava em propor uma estrutura de ensino mais atualizada, baseada no modelo integrado de ensino por blocos, que a Universidade de Western Reserv, em Cleveland, Estados Unidos, vinha experimentando há muitos anos, com divulgação internacional grande através de vários trabalhos em revistas especializadas. Assim, nasceu a proposta com dois objetivos: integração com a universidade e modernização do currículo (SILVA, 2001, p. 15).

O CEM-USP deveria se voltar para essas duas áreas, para esses dois tipos de médicos. Segundo Raw (1993/1994, p. 137):

\begin{abstract}
O curso experimental introduziu uma série de ideias como a integração da medicina clínica e social desde os primeiros anos do curso médico; os alunos deveriam aprender a partir de livros e revistas, na biblioteca e nos laboratórios, em contato com pesquisadores ativos, e, finalmente, a formação de importantes grupos de pesquisa liderados por docentes oriundos da Medicina [...]. Em nossa proposta à Opas, demos um possível exemplo do uso de focos de interesse para criar um curso básico destinado exclusivamente a estudantes de Medicina, que integra as ciências básicas, iniciação à clínica e à medicina social.
\end{abstract}

Nas palavras de Eduardo Marcondes (1995, p. 175), os objetivos gerais do CEM-USP no campo educacional primavam pela utilização de técnicas de ensino adequadas, contribuindo para o desenvolvimento da capacidade de estudar, de raciocinar e de trabalhar em grupo, sem desprezar o adestramento prático-manual ao exercício da medicina. Como também propiciar condições para a ampliação das opções para o estudante quanto às modalidades do exercício da profissão, oferecendo oportunidades para o desenvolvimento de uma mentalidade médica global, pela valorização de áreas gerais em relação às especializadas e do indivíduo como um todo psicossomático em relação à parte doente.

Naquilo que dizia respeito ao planejamento de ensino, em relação à Faculdade de Medicina, propunha-se testar novos métodos de ensino no currículo de graduação médica, fornecendo subsídios para uma constante renovação das técnicas docentes, promovendo, centralmente, a integração da Faculdade de Medicina na Universidade de São Paulo, contribuindo para uma nova formulação do ensino integrado de todos os currículos pertinentes à saúde, sendo considerado indispensável a existência do Hospital Universitário (MARCONDES, 1995, p. 175). No que tange à abordagem das Ciências Sociais em questões da Saúde, o 
que viria a ser caracterizado pela própria Donnangelo como uma Sociologia da Saúde, em consonância com a perspectiva mais prática e de ensino mais integral do CEM, a sua opção recaiu em uma disciplina que, para discutir as teorias sociais, valia-se de pesquisas operacionais e de campo com temas médicos, mais uma vez acentuando sua perspicácia pedagógica (DONNANGELO; PEREIRA, 1976; SCHRAIBER, 2011).

\section{Momentos de reação: quando o "Experimental" foi extinto}

Não há dúvida de que a concepção trazida pelo Curso Experimental ensejou forte oposição daqueles que entendiam haver uma divisão de poder na Faculdade de Medicina. Somavam-se ao fato os reflexos do período ditatorial, quando professores e alunos, muitos do CEM-USP, foram perseguidos, torturados e/ou perderam seus postos de trabalho. Essa conjuntura, eivada de "denuncismos" e com a avaliação de parte da instituição de que tal curso "não era capaz de refletir melhoria no ensino e na formação médica" teve seu desfecho em 30 de agosto de 1974, com a chegada à diretoria da Faculdade de Medicina de Carlos da Silva Lacaz, líder oponente daquilo que se chamava de "esfacelamento do curso médico". Com o apoio da Congregação da Faculdade, já em seu discurso de posse, ele pedia a constituição de uma Comissão para proceder ao encerramento do projeto do CEM-USP e sua incorporação ao curso tradicional, por um projeto chamado de "fusão curricular", a partir do ano de 1976.

O Departamento de Medicina Preventiva também não demorou a sofrer de forma mais contundente as refregas da política interna da instituição, por ações abertas e outras não tanto. Exemplarmente, um "autor desconhecido" redigiu o chamado Projeto de Ação da Faculdade de Medicina-USP no Centro de Saúde do Butantan, guardado por Carlos da Silva Lacaz num rico dossiê documental sobre aquele momento. Numa linguagem de inclinação policial, se tentava fazer uma avaliação da situação em que vivia a faculdade, com uma denúncia de tom bastante grave: “[...] o corpo docente do Departamento de Medicina Preventiva é todo ele composto de elementos politizados, adestrados em propaganda política e que já utilizaram o Centro de Saúde da Lapa para seus objetivos antinacionais" (PROJETO..., 1976, p. 2). Segundo essa narrativa, aquele grupo espalhado pelas capilaridades do Departamento era uma ameaça, sendo o Centro de Saúde do Butantan um polo especial de preocupação. Para deixar mais vivas as cores dos fatos, o programa de saúde mental recebeu a seguinte reserva: 
[...] a população a ser atendida pelo Centro de Saúde do Butantan gira em torno de 70.000 famílias, de nível socioeconômico baixo, constituída primordialmente por operários. Sabemos que, dentre as tarefas a serem empreendidas pelo Centro de Saúde do Butantan, está um programa de Saúde Mental. Sabemos também que os responsáveis pela área de Saúde Mental do Departamento de Medicina Preventiva são elementos reconhecidamente subversivos e com adestramento psicopolítico. Fica claro, portanto, o perigo que tal fato representa, pois é notório que esses elementos aproveitar-se-iam da situação para inocular na mente daquela população desfavorecida ideias radicais e instigadoras de rebelião (PROJETO..., 1976, p. 3, grifos nossos).

Finalmente, dentro de um quadro conjuntural desfavorável ao Departamento de Medicina Preventiva, uma ação abertamente ligada à disciplina ministrada por Cecília Donnangelo poria fim à sua experiência docente na graduação. Isso porque, junto com o projeto de fusão curricular, enviou-se ao então coordenador da Câmara de Graduação da USP um arrazoado sobre o fato de se terem permitido:

[...] distorções evidentes da atual estrutura curricular que não vêm atendendo às necessidades de ensino, cujo padrão, segundo os docentes, vem caindo assustadoramente. Disciplinas não pertinentes à formação do médico, como "Ciências Sociais", têm sido ministradas [...] [e se pedia a urgente] supressão da disciplina de Ciências Sociais, cujo conteúdo ministrado identifica-se ao ministrado em departamento da Faculdade de Filosofia, Letras e Ciências Humanas (CARTA..., 1976, p. 2).

Mesmo com pedidos oficiais à Congregação de Guilherme Rodrigues da Silva e de uma forte mobilização estudantil em apoio à disciplina, ela foi suprimida entre 1976 e $1977^{4}$. Essa nova conjuntura mudou a vida acadêmica de Donnangelo, que passou a desenvolver, sobretudo, atividades didáticas em nível de pós-graduação, inclusive assumindo a coordenação do curso de pós-graduação em Medicina Preventiva (AYRES; MOTA, 2012, p. 125-137). No entanto, muitas questões suscitadas por ela já vinham sendo incorporadas ao pensamento médico crítico, pelo movimento de renovação curricular do período e

4 Houve greve dos alunos entre 15 de outubro de 1976 e 11 de novembro de 1976. Entre os motivos dessa paralisação estavam as mudanças curriculares propostas pela Congregação da Faculdade, entre elas, o fim da disciplina de Ciências Sociais. 
por autoridades da área de saúde. Uma marca nascida também de sua capacidade de visão pedagógica, de pensar a educação médica e suas repercussões no país.

Durante esse turbulento processo, ela obteve, pelo Departamento de Medicina Preventiva, os títulos de doutora em ciências, com Medicina e sociedade: o médico e seu mercado de trabalho (1973), e de professora livre-docente, com Medicina e estrutura social: o campo da emergência da medicina comunitária $(1976)^{5}$. Em seu doutorado, rompendo com a ideologia liberalizante da profissão, logrou detectar a crescente tendência à proletarização dos médicos. Sua análise parte do conceito de atuação do Estado via Instituto Nacional de Assistência Médica da Previdência Social (Inamps) e do avanço do capitalismo no Brasil, quando se constituem as empresas médicas e o Estado passa a assegurar o mercado das empresas. Já na livre-docência, desenvolveu um trabalho essencialmente teórico, cuja preocupação maior era delimitar o objeto de estudo e análise da sociologia da saúde (MOTA; SCHRAIBER; SILVA, 2004, p. 27):

Sem dúvida, esse texto lança questões que seriam nucleares para os futuros estudos da medicina/saúde como prática social e sobre o processo de medicalização da sociedade. Certamente, a força do trabalho reside no fato de, diferente do estudo anterior, não ser um trabalho empírico, mas de construção teórica. Destaca-se que a apreensão da relação medicina/ produção capitalista é realizada quando o estudo estabelece a conexão entre prática médica e força de trabalho, que, segundo Luiz Pereira é estratégico para o "estudo das funções infraestruturais", como também para o "estudo de suas funções supraestruturais" (NUNES, 2008, p. 906).

Todo esse percurso teórico-educacional alimentou a incessante busca de Donnangelo pelo social, em caminhos construídos a partir das contingências, das rupturas necessárias, das permanências articuladoras do acontecimento e de sua singularidade. Olhar para essa esfera pela educação talvez revele algo novo a respeito de seu pensamento, que poderá ser devidamente estudado e aprofundado, já que é ainda pouco pesquisado em sua complexidade, mesmo com tantos rastros e pistas, como observou Schraiber (2011, p. 11-20):

Sua produção teórica inova em pelo menos três direções: sobre a medicina como prática em mercado; sobre a medicina como prática técnica

5 Publicados respectivamente como Medicina e sociedade: o médico e seu mercado de trabalho (pela editora Pioneira, em 1975) e Saúde e sociedade (pela editora Duas Cidades, em 1976). 
e social; sobre a medicina como prática de educação. Embora essas três direções se conectem como questões da relação entre o social e a medicina, e possam ser resgatadas como foco central de sua produção científica, as duas primeiras estão mais desenvolvidas e correspondem a seus dois livros (Medicina e sociedade: o médico e seu mercado de trabalho, de 1975; e Saúde e sociedade, de 1976), estando a terceira apenas preliminarmente explorada em um texto que escreveu acerca da prática de educação em saúde.

Ao fim e ao cabo, ao se recuperar historicamente seu percurso de pedagoga e educadora, quer para definir pontos de tensão e limites em sua experiência educacional, quer para apontar ações criativas capazes de implantar uma nova concepção na formação dos médicos, o importante é notar invariavelmente o aspecto social como eixo central de todo o seu investimento intelectual, este perfeitamente identificável em todo o seu percurso.

\section{REFERÊNCIAS}

ABREU, M. de A. Sobre a memória das cidades. Território, Rio de Janeiro, ano III, $\mathrm{n}$. 4, p. 5-26, jan./jun. 1998.

AYRES, J. R. de C. M.; MOTA, A. Departamento de Medicina Preventiva. In: MOTA, A.; MARINHO, M. G. S. M. C. (Org.). Departamentos da Faculdade de Medicina da Universidade de São Paulo. São Paulo: Casa de Soluções e Editora, 2012. v. 2. p. 125-137.

CANATO, C. ARENA e MDB em Araraquara (1965-1979). Dissertação (Mestrado em Ciência Política) - Instituto de Filosofia e Ciências Humanas, Universidade Estadual de Campinas, Campinas, 2003.

CARTA de Carlos da Silva Lacaz para Antônio Guimarães Ferri [Coordenador da Câmara de Graduação - USP], São Paulo, 27 out. 1976, p. 1. Mimeo. (Museu Histórico Prof. Carlos da Silva Lacaz - FMUSP).

CASTRO, C. P. de. Luiz Pereira e sua circunstância: entrevista com José de Souza Martins. Tempo Social, São Paulo, v. 22, n. 1, p. 211-276, 2010.

CERTEAU, M. de. A escrita da história. 3. ed. Rio de Janeiro: Forense, 2011.

DONNANGELO, M. C. Curriculum Vitae, 1982. Mimeo.

DONNANGELO, M. C.; PEREIRA, L. Saúde e sociedade. São Paulo: Duas Cidades, 1976. 
DOSSE, F. O desafio biográfico: escrever uma vida. São Paulo: Edusp: 2009.

FERREIRA, M. S. Os Centros de Pesquisas Educacionais do INEP e os estudos em ciências sociais sobre a educação no Brasil. Revista Brasileira de Educação, Rio de Janeiro, v. 13, n. 38, p. 279-292, maio/ago. 2008.

JACKSON, L. C. Gerações pioneiras na sociologia paulista (1934-1964). Tempo Social, São Paulo, v. 19, n. 1, p. 116-130, 2007.

LACAZ, C. da S. História da Faculdade de Medicina da USP: reminiscências, tradição, memória de minha escola. São Paulo: Atheneu, 1999.

MARCONDES, E. O Curso Experimental de Medicina da Universidade de São Paulo. Educación médica y salud, Washington, v. 9, n. 2, p. 172-195, 1995.

MEDINA JUNIOR, C. Bem-vindos a nossa história: Teatro Experimental de Comédia de Araraquara (1955-1962). Tese (Doutorado em Artes) - Instituto de Artes, Universidade Estadual de Campinas, Campinas, 2009.

MENDES-GONÇALVES, R. B. Cecília Donnangelo hoje. Saúde \& Sociedade, São Paulo, v. 1, n. 1, p. 3-5, 1992.

MENDONÇA, A. W. P. C. Pragmatismo e desenvolvimentismo no pensamento educacional brasileiro dos anos de 1950/1960. Revista Brasileira de Educação, Rio de Janeiro, v. 11, n. 31, p. 96-113, 2006.

MOTA, A.; SCHRAIBER, L. B.; SILVA, J. A. Contribuições pragmáticas para a organização dos recursos humanos em saúde e para a história da profissão médica no Brasil à obra de Maria Cecília Donnangelo. Brasília: Ministério da Saúde, 2004.

NUNES, E. D. Cecília Donnangelo: pioneira na construção teórica de um pensamento social em saúde. Ciência \& Saúde Coletiva, Rio de Janeiro, v. 13, n. 3, p. 909-16, 2008.

PEREIRA, L. Maria Cecília Donnangelo: seis lembranças e um depoimento. Medicina, Cultura \& Ciência, São Paulo, n. 5, p. 1-23, 1983.

PROJETO de ação da Faculdade de Medicina da USP no Centro de Saúde do Butantan, 1976. Manuscrito sem autoria. Mimeo. (Museu Histórico Prof. Carlos da Silva Lacaz - FMUSP).

RAW, I. Reformulação do ensino médico: Faculdade de Medicina e a USP. Revista da USP, São Paulo, n. 20, p. 131-137, 1993/1994.

RIBEIRO, M. A. R.; JUNQUEIRA, M. P. A saúde pública nas cidades de Rio Claro, São Carlos e Araraquara, em fins do século XIX. In: MOTA, A.; MARINHO, M. G. S. M. C. Práticas médicas e de saúde nos municípios paulistas: a história e suas interfaces. São Paulo: Casa de Soluções e Editora, 2011. p. 235-258.

SCHRAIBER, L. B. Prefácio. In: DONNANGELO, M. C.; PERREIRA, L. Saúde e Sociedade. São Paulo: Hucitec, 2011. p. 11-20. 
SILVA, G. R. (Depoimento). In: CHASSOT, W. C. F. (Org.). Memórias de origens: Hospital Universitário da Universidade de São Paulo, 20 anos. São Paulo: Hospital Universitário-USP, 2001.

SOUZA, R. F. de. O ensino secundário e a formação das elites na morada do sol: Araraquara-SP 1911-1950. São Paulo, 12 p. Mimeo.

VAIDERGORN, J. As seis irmãs. As Faculdades de Filosofia, Ciências e Letras: institutos isolados de ensino superior no estado de São Paulo - 1957-1964. Tese (Doutorado em Educação) - Faculdade de Educação, Universidade Estadual de Campinas, Campinas, 1995.

Texto recebido em 16 de setembro de 2014 . Texto aprovado em 15 de outubro de 2014. 